\title{
Street versions of opioids more potent and dangerous
}

$\mathrm{T}$ he increase in abuse of opioid pain medications, such as oxycodone and fentanyl, appears to be fuelling the illicit manufacture of derivatives that vary in composition and potency. The many unknowns surrounding these pills and powders make them far more dangerous than those produced by pharmaceutical companies. Though the diversion of drugs from the medical system to the streets is a serious problem, people who misuse legitimate medications at least know what they are putting in their bodies.

"It's not good in any way for someone to abuse a medically produced opioid analgesic, but it's probably even worse to use something that is illicitly produced," says Benedikt Fischer, director of the Centre for Applied Research in Mental Health and Addiction at Simon Fraser University in Vancouver, British Columbia. "Fentanyl is a very potent drug. Its onset of action is strong and rapid. This is a very risky drug to monkey with."'

Those risks, though, aren't deterring street drug peddlers. In April, during a drug raid in Montréal, Quebec, police found 12400 pills of desmethyl fentanyl, an illicit derivative of fentanyl that is 40 times more powerful than heroin, reported the Montreal Gazette. According to the Gazette, it was the first time the drug had ever been seized in Canada.

Deadly derivatives of fentanyl have also been found in the United States, traced to clandestine labs located domestically or in Mexico, according to the Drug Enforcement Administration. And like the fentanyl derivative seized in Montréal, they tend to be extremely powerful.

"This clandestinely produced fentanyl is 100 times more potent than the legitimate medication," Barara Carreno, a public affairs officer with the US administration, writes in an email. "We always see a surge in the summer months here in America of overdose deaths from heroin cut with fentanyl."

Fentanyl, commonly used in patch form by people who suffer chronic

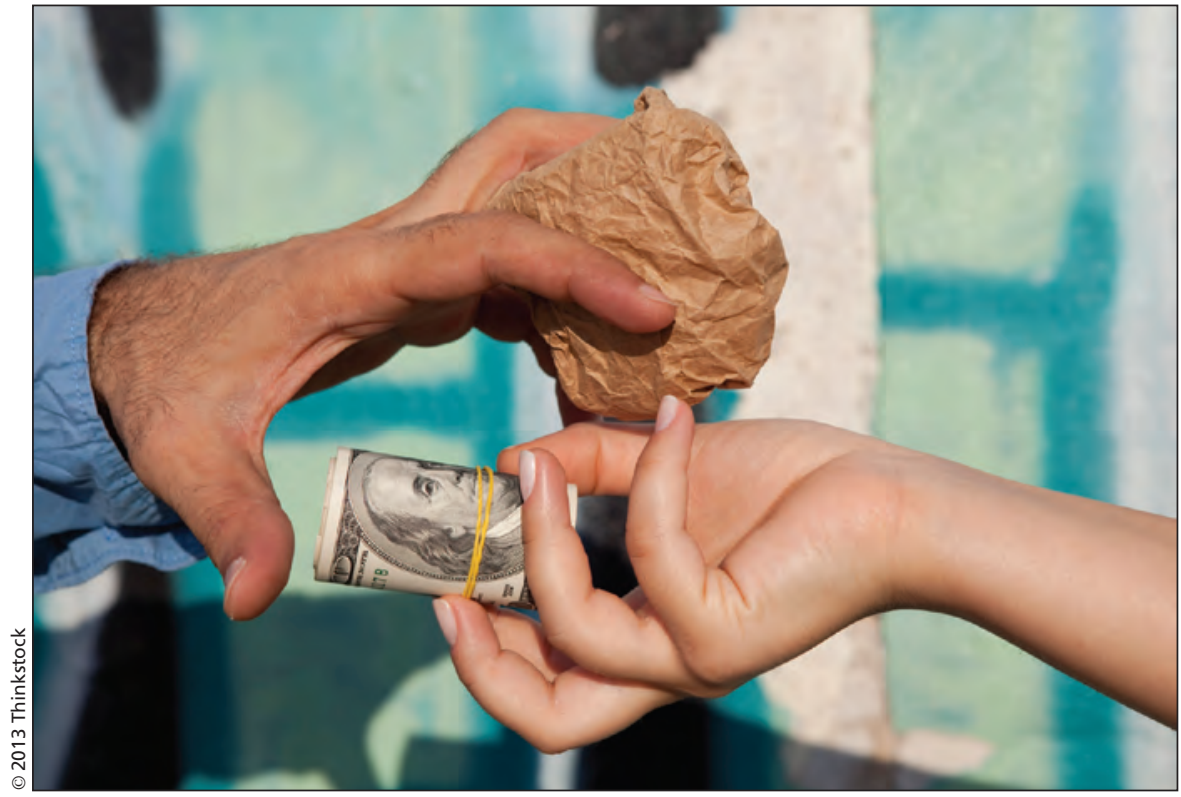

The many unknowns surrounding illicitly produced opioids make them far more dangerous than those produced by legitimate pharmaceutical companies.

pain, is already a dangerous product if misused, note drug experts. When a derivative is cooked up in somebody's garage - or some other back-alley facility unlikely to uphold strong quality-assurance standards - the risks increase. The same holds true for any illicitly made knock-off of a legitimate medicine, says Matthew Young, senior researcher and policy analyst for the Canadian Centre on Substance Abuse.

"There are so many unknowns," says Young. "People don't know how much to take. They don't know how potent it is. They don't even know what they are taking."

Very little is known about the prevalence of use of illicitly produced opioids. What is known, however, is that street drug users have developed a liking for opioids in recent years. "Over the past 10 years or so, prescription opioids, meaning medical opioids that are diverted, have more or less replaced heroin among street drug users," says Fischer. "The patterns you see of what goes on in the street market are typically fuelled and fed by general patterns you see of dispensing through the medical system."'
It should perhaps come as little surprise that street versions of these drugs would arise to meet demand. Use of illicitly produced fentanyl may be increasing in British Columbia, for example. There were 23 deaths in the province related to fentanyl in the first four months of 2013, compared to 20 for all of 2012, prompting the ministry of health to issue a warning to health workers to "be watchful for potential overdoses associated with the drug fentanyl."

The riskier nature of street drugs is already scaring away younger customers, according to Marc Paris, executive director of the Partnership for a Drug Free Canada. Teenagers appear to be turning to the family medicine cabinet instead. "The current trend with teenagers is more towards misusing prescription drugs to get high," Paris writes in an email. "One of the main reasons is that they feel that they are safer than street drugs. Another reason is that the medicine cabinet has become the new source for free drugs." Roger Collier, CMAJ

CMAJ 2013. DOI:10.1503/cmaj.109-4535 